\title{
João Tuna e a fotografia de cena como obra de arte
}

\section{Jorge Louraço Figueira}

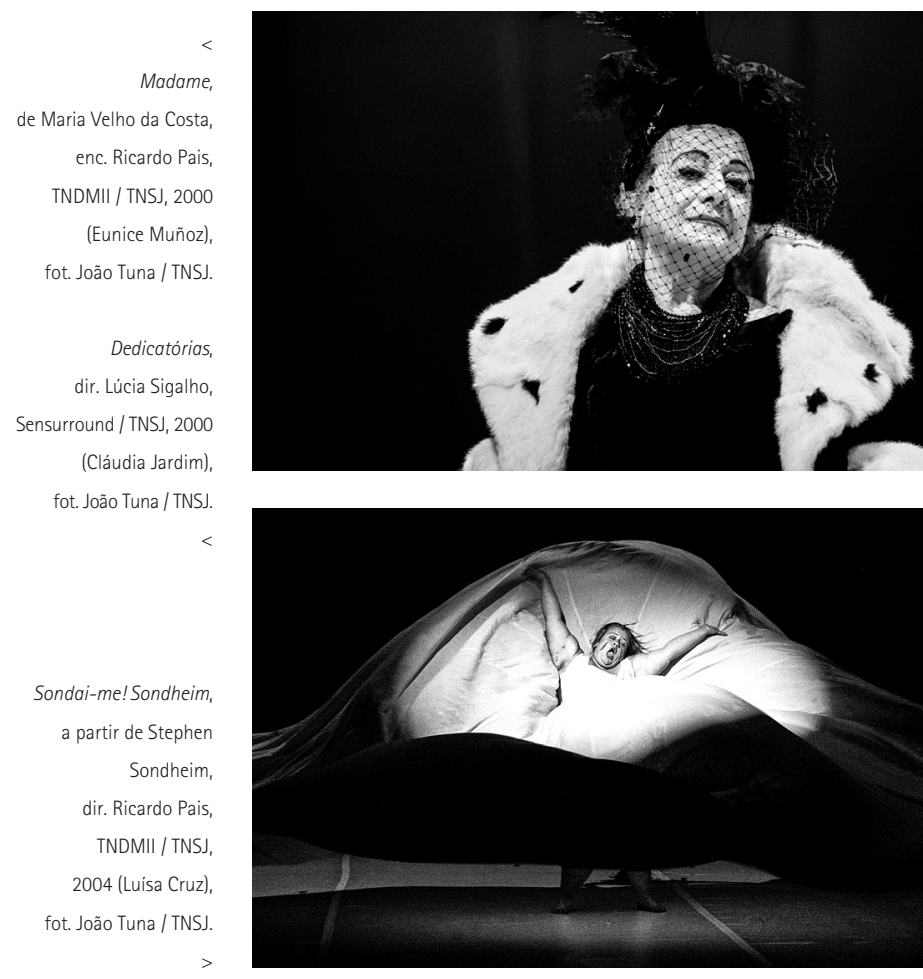

A fotografia de cena é o mais fiel depositário das obras teatrais: poder-se-ia dizer isto ao ver o livro que reúne as fotos de João Tuna, Todos os fantasmas usam botas pretas, Rastros: TNSJ 1996 - 2009 (TNSJ, 2012). Porém a cumplicidade dele com os actores, encenadores, cenógrafos e iluminadores, entre outros artistas, que fotografou ao longo dos anos, vai muito além da objetiva. Os espetáculos registados parece que só ficaram completos depois da invenção de imagens deste fotógrafo, cineasta e dramaturgo, cuja visão do mundo é um teatro por si só. Essas obras de arte - as fotografias - possuem

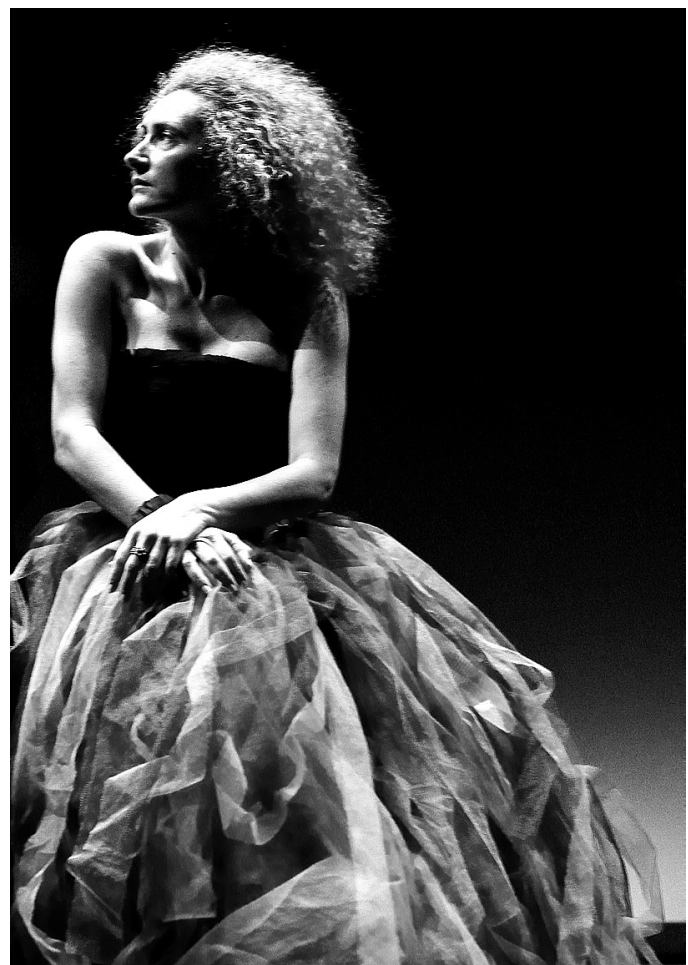

um mérito artístico próprio, que a Associação Portuguesa de Críticos de Teatro pretende reconhecer com esta Menção Especial.

Além da fotografia, João Tuna estudou cinema e dramaturgia, e é autor de vários filmes e textos de teatro. Tuna está numa posição de charneira entre estas artes, o que lhe permite fotografar como quem escreve, escrever como quem filma e filmar como quem fotografa. 0 artista extrai o melhor de cada uma dessas práticas e, talvez mais importante, faz com grande sabedoria e extrema sensibilidade o cruzamento entre elas. 


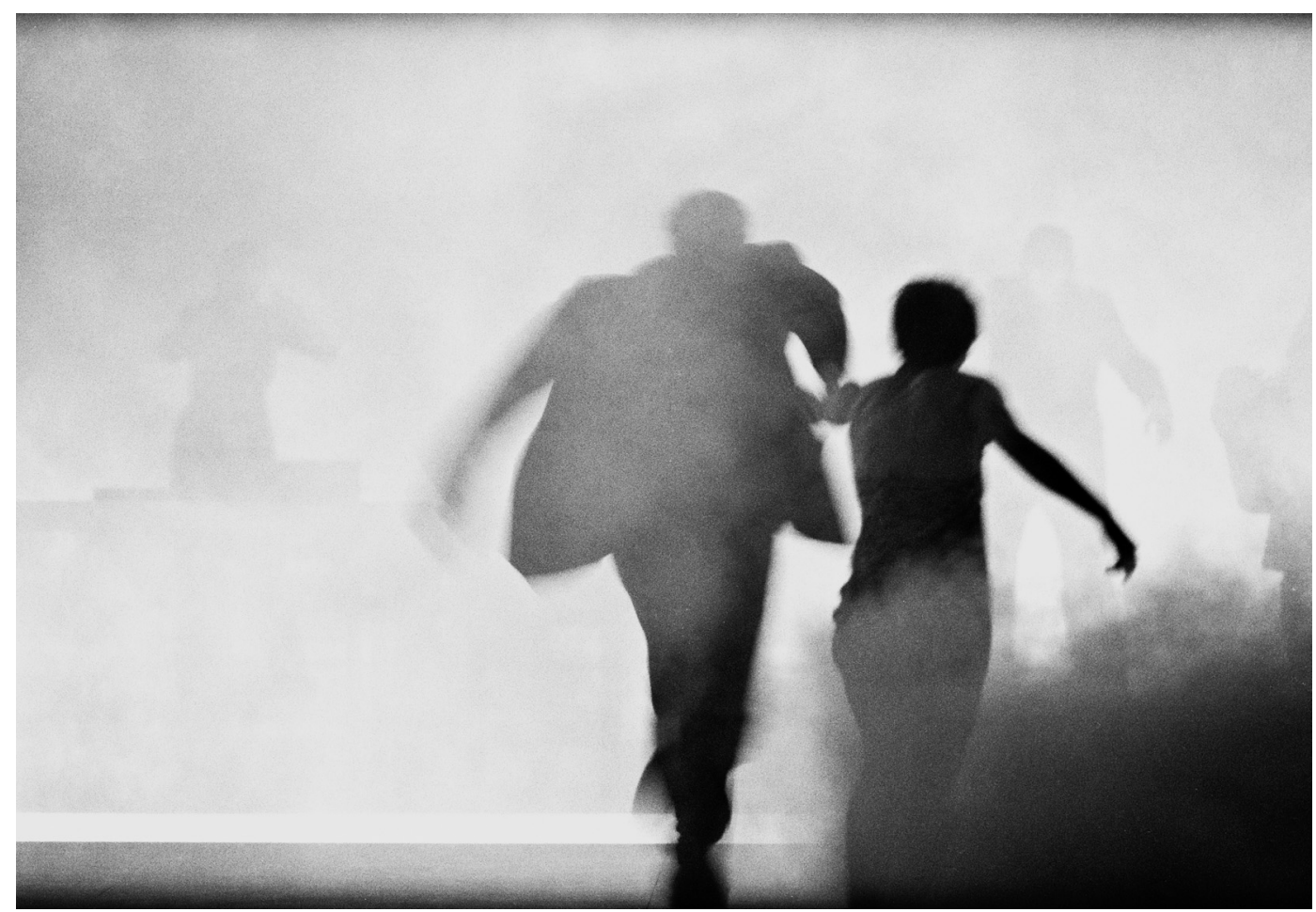

Frei Luis de Sousa,

de Almeida Garrett, enc. José Wallenstein, TNSJ, 2001

(Margarida Gonçalves e Nuno Melo), fot. João Tuna / TNSJ.
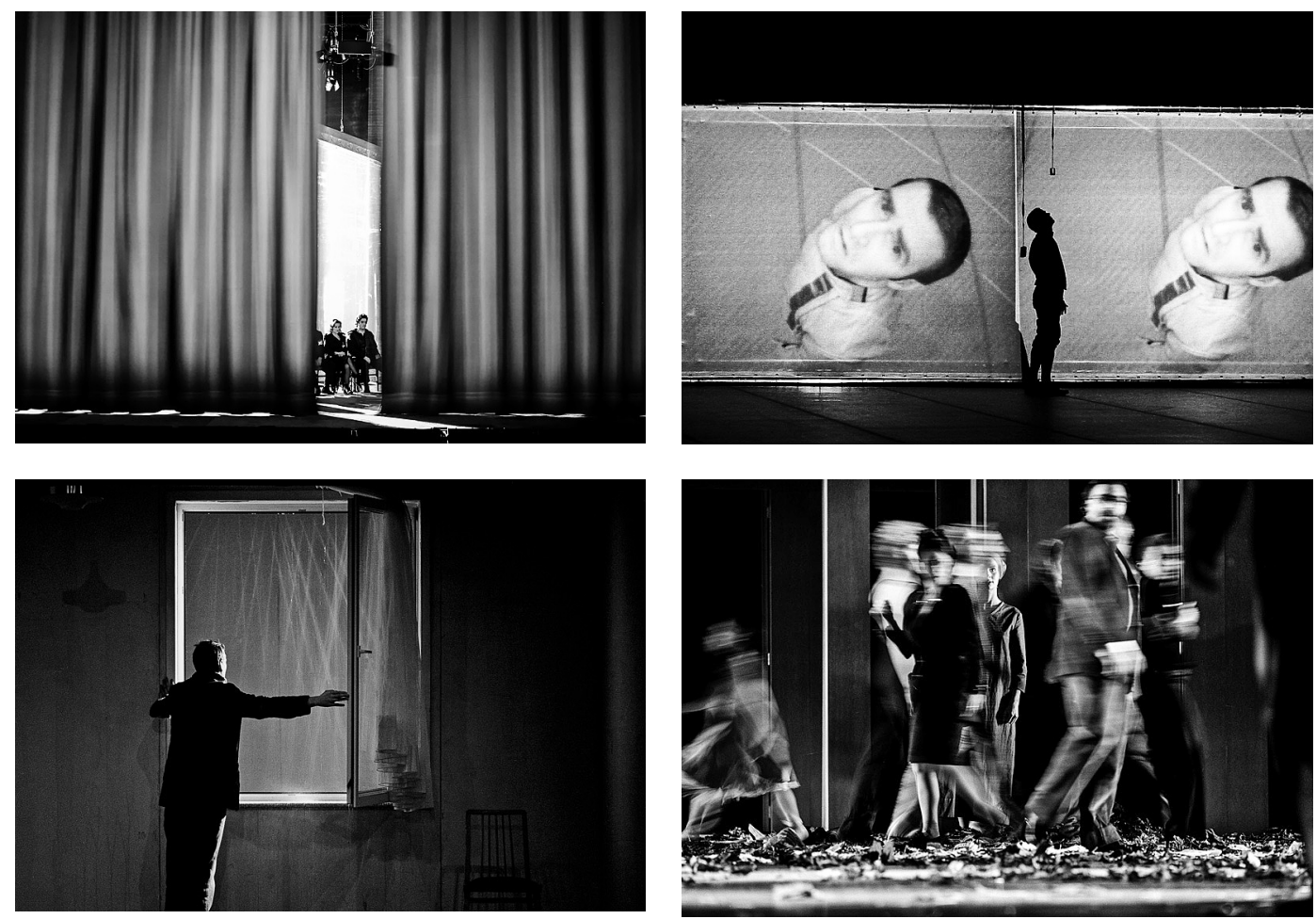

No Porto, onde trabalha há mais de uma década, Tuna tem feito o acompanhamento das produções próprias e acolhimentos do Teatro Nacional São João com notável espírito de missão, levando a cabo um trabalho de verdadeiro serviço público, sempre em busca da excelência, em nome da arte e da instituição. Não se trata de um mero trabalho de registo, mas de um trabalho de alargamento do âmbito das criações apresentadas. As fotografias perduram mais no tempo e circulam mais no espaço que os espetáculos, e é assim que se expandem as obras originais para lá da sua condição de peça de teatro.

E ainda além disso, o que poderia ser um mero registo tem significados cénicos que a própria cena não tinha inicialmente, e não teria jamais, e que são criados pelo fotógrafo de cena a partir do espetáculo, como obras de arte em si mesmas. A distinção com que João Tuna cria as suas imagens dá-nos orgulho na instituição pública e esperança na arte.
Der Name, de Jon Fosse, enc. Thomas Ostermeier, co-produção Schaubühne am Lehniner Platz / Salzburger Festspiele, 2001, fot. João Tuna / TNSJ.

A hora em que não

sabiamos nada uns dos outros,

de Peter Handke, enc. José Wallenstein, Teatro Só / TNSJ, 2001 (Cecilia Laranjeiro), fot. João Tuna / TNSJ 